УДК 621.745.3:662.925

ПОВЫШЕНИЕ ЭНЕРГОЭФФЕКТИВНОСТИ ПЛАВИЛЬНОЙ ПЕЧИ

IMPROVING THE ENERGY EFFICIENCY OF THE SMELTER

\author{
С.Г. Прохоров, С.А. Глазунов
}

Пензенский государственный университет архитектуры и строительства, г. Пенза, Российская Федерация

Sergey G. Prokhorov, Stanislav A. Glazunov

Penza State University of Architecture and Construction, Penza, Russian Federation

\title{
e-mail: tgv@pguas.ru
}

Аннотация. Печи машиностроительных предприятий характеризуются недостаточно эффективным использованием газового топлива в контексте современных требований по энергосбережению. Основным ресурсом повышения энергоэффективности печей является теплота дымовых газов. Одним из вариантов использования теплоты является возвращение части ее в печи с дутьевым воздухом, подаваемым на горение. В статье приводится расчет параметров дымовых газов на примере печи для плавки алюминия, оборудованной двумя горелками с номинальной мощностью 1,6 МВт. Применительно к параметрам дымовых газов разработан радиационный ударно-щелевой рекуператор со струйным натеканием теплоносителей для подогрева дутьевого воздуха.

Abstract. Furnaces of machine-building enterprises are characterized by insufficiently efficient use of gas fuel in the context of modern requirements for energy saving. The main resource for improving the energy efficiency of furnaces 
is the heat of flue gases. One option for the use of heat is to return part of its furnace blast air supplied for combustion. The article presents the calculation of flue gas parameters on the example of an aluminum smelting furnace equipped with two burners with a nominal capacity of 1.6 MW. In relation to the parameters of flue gases, a radiation shock-slit recuperator with a jet flow of heat carriers for heating the blowing air has been developed.

Ключевые слова: плавильная печь; подогрев дутьевого воздуха; конструкция рекуператора

Key words: smelter; heating of blast air; design of the heat exchanger

На одном из предприятий г. Пензы (Россия) в технологическом процессе плавки алюминия используется печь, оборудованная двумя блочными горелками с номинальной мощностью 1,6 МВт.

Требовалось рассчитать объем уходящих газов и предложить мероприятия по повышению эффективности использования газового топлива.

\section{Исходные данные}

1. Топливо - сетевой природный газ среднего состава.

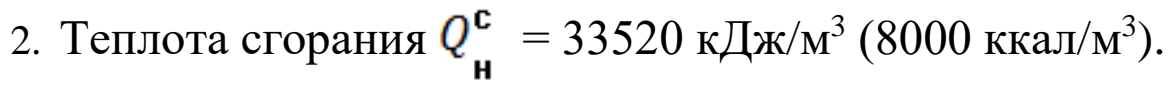

3. Теоретическое количество воздуха для горения $V_{\mathbf{B}}^{o}=9,5 \mathrm{~m}^{3} / \mathrm{m}^{3}$.

4. Теоретический объем дымовых газов $V_{\mathbf{r}}^{o}=10,5 \mathrm{~m}^{3} / \mathrm{m}^{3}$.

5. Количество n и мощность $Q_{2}$ установленных горелок -2 х 1.6 МВт.

6. Коэффициент избытка воздуха в камере сгорания $\alpha=1,1$.

7. Температура дымовых газов на выходе из печи $=900{ }^{\circ} \mathrm{C}$.

8. Температура дымовых газов перед дымососами $t_{1} g r^{\tau_{m}}=200{ }^{\circ} \mathrm{C}$.

9. Температура холодного воздуха $t_{x \varepsilon}=10^{\circ} \mathrm{C}$. 


\section{Расчет}

1. Расход газа на горелки при номинальной мощности

$$
B_{p}=\frac{n \cdot Q_{\mathrm{r}} \cdot 1000 \cdot 3600}{Q_{\mathrm{H}}^{C}}=\frac{2 \cdot 1.6 \cdot 1000 \cdot 3600}{33520}=343.7 \frac{\mathrm{HM}^{3}}{\mathrm{ч}} .
$$

2. Расход дымовых газов на выходе из печи при нормальных условиях

$$
V_{g_{\Gamma}}^{\mathrm{Hy}}=B_{p}\left[V_{\Gamma}^{0}+(\alpha-1) V_{\mathrm{B}}^{0}\right]=343,7[10,5+(1,1-1) 9,5]=3935,4 \frac{\mathrm{HM}^{3}}{\mathrm{ч}} .
$$

3. Расход дымовых газов на выходе из печи при температуре $900{ }^{\circ} \mathrm{C}$

$$
V_{g \Gamma}^{900}=V_{g \Gamma}^{\mathrm{Hy}}\left(\frac{273+t_{g \Gamma}^{\prime}}{273}\right)=3935,4\left(\frac{273+900}{273}\right)=16909,2 \frac{\mathrm{m}^{3}}{\mathrm{q}} .
$$

4. Коэффициент подмешивания

$$
u=\frac{t_{g \mathrm{r}}^{\prime}-t_{g \Gamma}^{\prime \prime}}{t_{g \mathrm{\Gamma}}^{\prime \prime}-t_{g_{\mathrm{\Gamma}}}}=\frac{900-200}{200-10}=3.68
$$

5. Расход дымовых газов перед дымососами

$$
V_{g \Gamma}^{200}=u \cdot V_{g \Gamma}^{900}=3,68 \cdot 16909,2=62225,8 \frac{\mathrm{m}^{3}}{ч} .
$$

Из расчета видно, что обеспечение надежности работы дымососов путем разбавления дымовых газов холодным воздухом не отвечает современным требованиям по энергоэффективности и энергосбережению, но мотивируется возможностью эксплуатационного маневра (дымососы могут быть использованы при увеличении производительности примерно на $30 \%$ при снижении развиваемого давления, при условии постоянства числа оборотов - примерно на 40 \%; при уменьшении производительности примерно на 50 \% при повышении развиваемого давления на 15-20 \% [1]).

Для рассмотрения на предпроектной стадии нами предложены следующие возможные пути повышения эффективности использования газового топлива в плавильной печи: 
- подогрев воздуха, подаваемого на горение при помощи рекуператора, регенератора или рекуперативных горелок (частичное использование теплоты дымовых газов);

- подогрев дутьевого воздуха, затем подогрев воды в водонагревателе на технологические нужды (более глубокая утилизация);

- подогрев дутьевого воздуха, подогрев воздуха на цели воздушного отопления, подогрев воды (полная утилизация).

Реализация той или иной схемы утилизации теплоты дымовых газов определяется возможностями предприятия, но подогрев дутьевого воздуха обязателен в современных печах. Долю физической теплоты дымовых газов, затраченной на нагрев воздуха, можно подсчитать по упрощенной методике [2] по формуле:

$$
q=\frac{100-q_{5}}{100}\left[0,01 z\left(t_{1}-t_{2}\right)\right]
$$

где $q_{5}-$ потери теплоты в окружающую среду в воздухоподогревателе, \%;

$t_{1}$ и $t_{2}$ - температура дымовых газов до и после воз-духоподогревателя, ${ }^{\circ} \mathrm{C}$;

$z$ - коэффициент, зависящий от температуры дымовых газов и степени их разбавления избыточным воздухом.

Применительно к параметрам дымовых газов печи на кафедре теплогазоснабжении и вентиляции разработан радиационный ударнощелевой рекуператор (рисунок 1) со струйным натеканием теплоносителей [3].

Радиационная секция имеет внутренний и наружный стальные цилиндры диаметром 700 и 800 мм соответственно, между ними установлен перфорированный цилиндр диаметром 788 мм. 


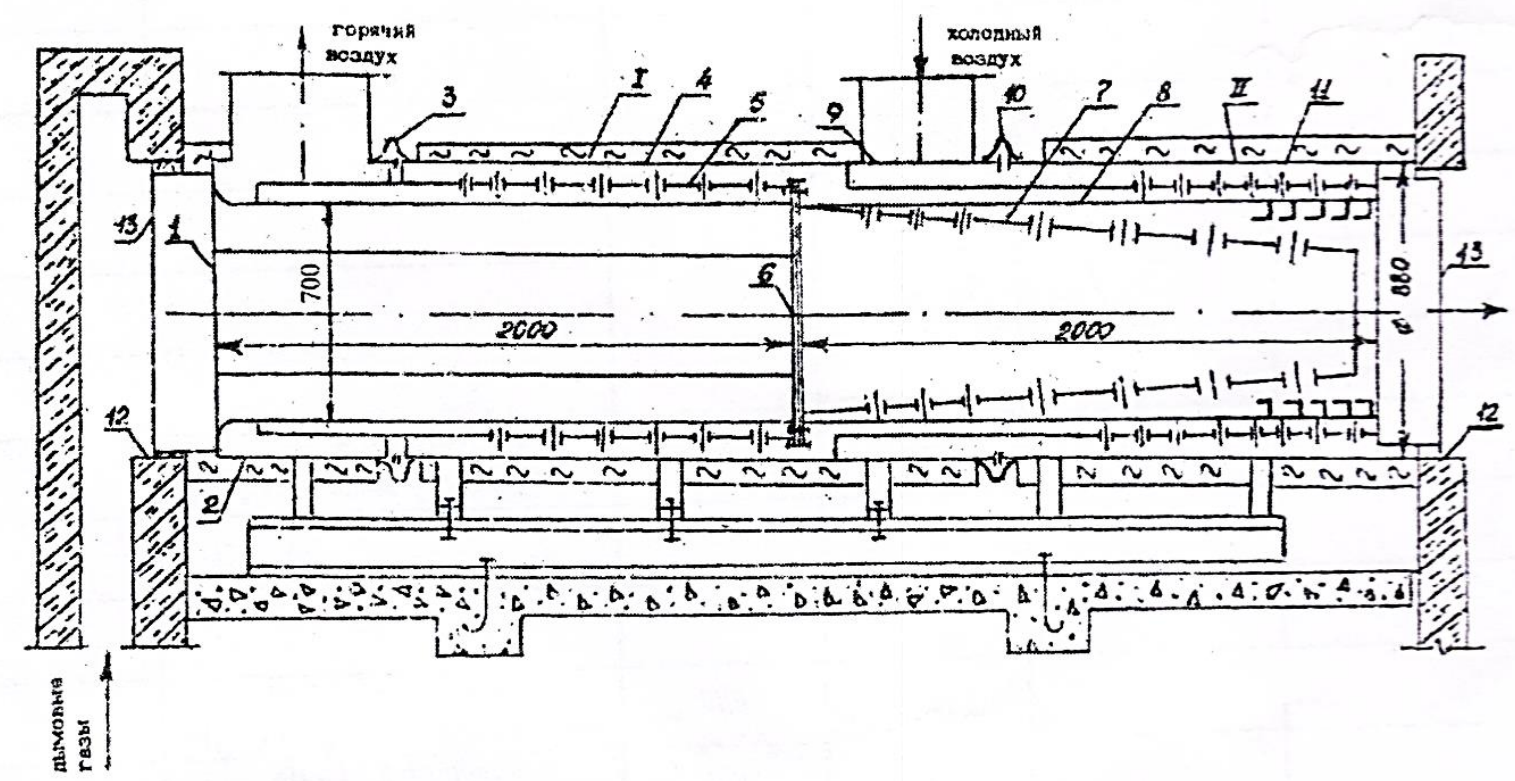

I - радиационная секция; II - ударно-щелевая секция;

1 - торцевой лист внутреннего цилиндра; 2, 9 - обечайки;

3, 10 - линзовые компенсаторы; 4, 11 - корпуса;

5 - перфорированный цилиндр;

6 - опорный лист внутреннего цилиндра;

7 - перфорированный конус;

8 - внутренний цилиндр ударно-щелевой секции;

12 - цилиндры герметизации; 13 - ножи

Рисунок 1. Радиационный ударно-щелевой рекуператор

Для увеличения теплоотдачи от дымовых газов на внутренней поверхности внутреннего цилиндра приварены ребра. Со стороны воздуха осуществляется струйное натекание.

Ударно-щелевая секция построена из трех цилиндров аналогично радиационной секции. Во внутренний цилиндр вставлен перфорированный конус, закрытый с узкого торца. С помощью конуса осуществляется струйное натекание дымовых газов на теплообменную поверхность. Обе секции снабжены однолинзовыми компенсаторами и теплоизолированы.

Дымовые газы входят во внутренний цилиндр радиационной секции, проходят ее и направляются в перфорированный конус. Из конуса дымовые газы натекают через отверстия на внутреннюю поверхность внутреннего цилиндра ударно-щелевой секции и уходят в дымовой боров. Холодный воздух подводится через входной патрубок ударно-щелевой секции и натекает струями на внешнюю поверхность внутреннего цилиндра. Далее 
воздух поступает в радиационную секцию, где натекает на наружную поверхность внутреннего цилиндра и выводится через выходной патрубок.

\section{Техническая характеристика}

Режим работы - по режиму печи.

1. Температура дымовых газов перед рекуператором $-800-1000{ }^{\circ} \mathrm{C}$.

2. Расчетный расход дымовых газов - 1,44 кг/с или 4000 нм³/ч.

3. Максимальная температура подогрева воздуха при расчетной температуре дымовых газов $800^{\circ} \mathrm{C}$ составляет $200{ }^{\circ} \mathrm{C}$.

4. Количество нагреваемого воздуха - 1,8 кг/с или 5000 нм³/ч.

5. Сопротивление по дымовому тракту при расчетном расходе дымовых газов - 135 Па.

6. Сопротивление по воздушному тракту при расчетном расходе воздуха -1649 Па.

7. Тепловая мощность -416 кВт.

8. Состав рекуператора - радиационная секция и ударно-щелевая секция.

9. Наружный диаметр дымового цилиндра секции - 0,7 м.

10. Длина цилиндра дымового тракта каждой секции - 2,0 м.

11. Общая длина рекуператора $-4,0$ м.

Разработаны рабочие чертежи рекуператора, позволяющие изготовить его в качестве нестандартного оборудования.

\section{Выводы}

Высокотемпературные дымовые газы плавильной печи объективно имеют потенциал в контексте энергосбережения. Предложены возможные пути частичной и полной утилизации теплоты дымовых газов. Разработанный рекуператор для подогрева дутьевого воздуха позволит повысить энергоэффективность работы печи. 


\section{Список используемых источников}

1. Сенчев В.Г., Александрович Ю.Б., Аушев В.С., Янин В.П. Справочник энергетика строительной организации: В 2 Т. Тепло-, водо- и воздухоснабжение строительства. М.: Стройиздат, 1991. Т. 2. 511 с.

2. Равич М.Б. Газ и эффективность его использования в народном хозяйстве. М.: Недра, 1987. 237 с.

3. Прохоров С.Г., Аржаева Н.В., Родионов Ю.В., Кожунов А.А. Совершенствование струйных рекуператоров // Научный вестник Воронежского государственного архитектурно-строительного университета. Строительство и архитектура. 2013. № 2 (30). С. 27-33.

\section{References}

1. Senchev V.G., Aleksandrovich Yu.B., Aushev V.S., Yanin V.P. Spravochnik energetika stroitel'noi organizatsii: $V 2$ T. Teplo-, vodo- $i$ vozdukhosnabzhenie stroitel'stva [Power Engineering Handbook of a Construction Organization: In 2 Volumes. Heat, Water and Air Supply of Construction]. Moscow, Stroiizdat Publ., 1991, Vol. 2. 511 p. [in Russian].

2. Ravich M.B. Gaz i effektivnost' ego ispol'zovaniya v narodnom khozyaistve [Gas and the Efficiency of its Use in the National Economy]. Moscow, Nedra Publ., 1987. 237 p. [in Russian].

3. Prokhorov S.G., Arzhaeva N.V., Rodionov Yu.V., Kozhunov A.A. Sovershenstvovanie struinykh rekuperatorov [Improving Jet Recuperators]. Nauchnyi vestnik Voronezhskogo gosudarstvennogo arkhitekturno-stroitel'nogo universiteta. Stroitel'stvo i arkhitektura - Scientific Herald of the Voronezh State University of Architecture and Civil Engineering. Construction and Architecture, 2013, No. 2 (30), pp. 27-33. [in Russian]. 


\section{Сведения об авторах}

\section{About the authors}

Прохоров Сергей Григорьевич, кандидат технических наук, доцент кафедры «Теплогазоснабжение и вентиляция», Пензенский государственный университет архитектуры и строительства, г. Пенза, Российская Федерация

Sergey G. Prokhorov, Candidate of Engineering Sciences, Assistant Professor of Heat and Gas Supply and Ventilation Department, Penza State University of Architecture and Construction, Penza, Russian Federation

e-mail:tgv@pguas.ru

Глазунов Станислав Алексеевич, магистрант кафедры «Теплогазоснабжение и вентиляция», Пензенский государственный университет архитектуры и строительства, г. Пенза, Российская Федерация

Stanislav A. Glazunov, Undergraduate Student of Heat and Gas Supply and Ventilation Department, Penza State University of Architecture and Construction, Penza, Russian Federation

e-mail: tgv@pguas.ru 